\title{
Producing Daily and Embedded Hourly Rainfall Data Using a Novel Weather Generator
}

\author{
Ching-Pin Tung *, Wan-Yu Lien, and Wei-Ting Liao \\ Department of Bioenvironmental Systems Engineering, National Taiwan University, Taipei, Taiwan
}

Received 19 July 2012, accepted 14 November 2012

\begin{abstract}
The number of worldwide extreme drought and flood events has risen significantly in recent years. Many studies confer that climate change may cause more intensive and extreme events. Simulating the impact of climate change often requires weather data as inputs to assessment models. Stochastic weather generators have been developed to produce weather data with the same temporal resolution based on the outputs of GCMs. Reservoir simulation normally uses operational rules in daily and hourly time steps for water supply and flood reduction, respectively. Simulating consecutive drought and flood events simultaneously requires a weather generator to produce different temporal resolution data. This work develops a continuous weather generator to generate daily and hourly precipitation data for regular wet days and severe storms, respectively. Daily rainfall data is generated for regular wet days using Exponential distribution or Weibull distribution, while the total rainfall data for severe storms is generated using the Pearson type III or Log Pearson type III distribution. Moreover, hourly rainfall is determined based on generated hyetographs. Simulation results indicate that the proposed continuous weather generator can generate daily and hourly rainfall reasonably. The proposed weather generator is thus highly promising for use in evaluating how climate change impacts reservoir operations that are significantly influenced by more frequent and intensive consecutive drought and flood events.
\end{abstract}

Key words: Weather generator, Heavy rainfall, Storm, Reservoir, Climate change

Citation: Tung , C. P., W. Y. Lien, and W. T. Liao, 2013: Producing daily and embedded hourly rainfall data using a novel weather generator. Terr. Atmos. Ocean. Sci., 24, 437-450, doi: 10.3319/TAO.2012.11.14.01(Hy)

\section{INTRODUCTION}

Recent extreme weather induced disasters have drawn considerable attention, warranting further research on climate change impact assessment. Climate change impact areas such as hydrology, agricultural production, ecosystem and water resources management are often evaluated using simulation models that require weather data as inputs. Daily weather data are normally used for continuous simulation, while hourly data may be required for simulating extreme events, such as inundation or flood reduction operations of a reservoir. Due to unavailability, future weather data are often generated based on possible climate scenarios. Most research derives future climate scenarios (e.g., monthly weather statistics) based on outputs of General Circulation Models (GCMs). Downscaling methods and weather gen-

\footnotetext{
* Corresponding author

E-mail: cptung@ntu.edu.tw
}

erators are subsequently used to produce weather data with finer spatial and temporal resolutions (Wilks and Wilby 1999; Hansen 2002; Dubrovsky et al. 2005). The generated weather data must keep weather statistics of climate scenarios to account for extremes and seasonality (Kilsby 2007).

Climate change may significantly influence water resources systems, resulting in changes in water availability (IPCC 2007). Many studies have indicated that climate change may cause more and stronger extreme droughts and flood events, creating further challenges for water resources management. Such problems may be further exacerbated for a reservoir with a small capacity. In Taiwan a single typhoon induced rainfall can refill a dried out reservoir. Most related studies address either drought or flood issues independently (Li et al. 2010; Nagesh Kumar et al. 2010; Araghinejad 2011; Lee et al. 2012). Recent observations show severe flood events may occur immediately after a drought. Meanwhile, a serious drought may occur immediately after 
severe flood events. For instance, a serious drought occurred in southern Taiwan in the fall of 2009. As the major reservoir of southern Taiwan, Tsengwen reservoir had only $25 \%$ of its capacity full as of August 8, 2009. Later, an extreme rainfall event induced by Typhoon Morakot brought a total rainfall amount of $1643.5 \mathrm{~mm}$ within 48 hours and triggered the reservoir to operate in a hourly time step in order to release flash flood water. The reservoir almost had an overtopping event because the active capacity is only around 0.5 billion cubic meters. Following the severe storm the reservoir storage significantly decreased again due to extremely limited rainfall and high water demand. In 2001 Typhoon Nari struck northern Taiwan and seriously inundated the metropolitan Taipei area with the return period more than 100 years. Two months later the drought worsened in the same area due to very limited rainfall, small reservoir capacity and high irrigation water demand. Recent works on how climate-induced disasters impact reservoirs stress the importance of continuous drought and flood event simulation in an impact assessment study. However, the reservoir operation time steps for flood reduction and water supply are different and normally are hourly and daily time steps, respectively.

Despite their availability, many weather generators can only produce a series of weather data with the same time step. Pickering et al. (1994) developed a widely used weather generator to produce daily weather data, in which conditional wet day probability is used to generate wet day events. This generator was also involved an inverse rainfall cumulative probability function to produce daily rainfall for a wet day, as well as using an autoregression model to generate a daily mean temperature. Weather generators can be categorized into parametric (Parlange and Katz 2000; Fowler et al. 2007; Semenov 2008; Zhang et al. 2011) or non-parametric forms (Sharma et al. 1997; Mehrotra and Sharma 2007; Eum and Simonovic 2010). Three widely adopted weather generators include WGEN, LARS-WG and K-Nearest Neighbor (K-NN) weather generator.

The WGEN and LARS-WG models are parametric methods. WGEN is based on a procedure described by Richardson (1981). Richardson and Wright (1984) used the publicly available version of WGEN. Daily precipitation is generated using a 2-parameter gamma distribution in WGEN. However, LARS-WG is based on the study of Racsko et al. (1991), with detailed descriptions provided in Semenov et al. (1998) and Semenov and Brooks (1999). Using a semiempirical distribution LARS-WG determines the amount of precipitation. As a nonparametric method, the K-NN weather generator avoids the difficulties in fitting parameters and relevant parametric problems. This model typically begins with generating the first daily data randomly from the observed data set and a specified number of days by comparing the current day with its neighboring days (Eum and Simonovic 2010). Although capable of avoiding the difficulties in determining model parameters, this method takes a considerable amount of time in comparing the weather data for the next day with the entire database. Moreover, the range of historical weather data limits the generation of possible extreme events. If not recorded previously, a statistically possible extreme event is not generated, possibly resulting in underestimation of extreme events.

The frequency and magnitude of extreme weather events are likely to increase under climate change (Solomon 2007). Therefore, the ability of weather generators to produce extreme weather events must be verified before applicable to climate change studies. Kyselý and Dubrovský (2005) evaluated the ability of a weather generation model based on the first-order autoregressive (AR) model to generate extreme events, indicating that this model is limited in reproducing most daily values of extreme events. Semenov et al. (1998) indicated that LARS-WG tends to underestimate the variance in monthly means of some variables, owing to a simple auto-correlation structure. In addition to using semi-empirical distribution to generate precipitation and radiation data, LARS-WG applies normal distribution to simulate temperatures. However, the means of reproducing maximum daily temperature is less than observations. Thus, while attempting to reproduce extreme events data, Semenov (2008) suggested two possible solutions: using the generalized extreme value (GEV) distribution fitting the observed and synthetic data to estimate the return values or using semi-empirical distribution for temperature. Three parameters (i.e., $\mu, \sigma, \xi)$ are estimated in the GEV distribution for observed and synthetic data, where $\mu$ is location parameter; $\sigma$ is the scale parameter; and $\xi$ is the shape parameter governing the tail behavior of the distribution (Payne et al. 2007). Furrer and Katz (2008) also discussed the feasibility of advanced statistical methods to increase the simulation accuracy of extreme precipitation, such as a hybrid technique with a gamma distribution and a generalized $\mathrm{Pa}$ reto distribution. However, above works can only provide weather data in the same temporal resolution.

Many works have already demonstrated that climate change significantly impacts water resources, especially reservoirs (Wood et al. 1997; Hamlet and Lettenmaier 1999; Payne et al. 2004; Simonovic and Li 2004; VanRheenen et al. 2004; Eum and Simonovic 2010; Li et al. 2012). In addition to providing a water supply, a reservoir stores high inflows during a severe storm to protect downstream areas from flooding. Evaluating these functions simultaneously requires daily and hourly rainfall to model daily water supply and hourly flood reduction operations, respectively. Therefore, this work develops a continuous weather generator to provide daily and embedded hourly precipitation data for the continuous simulations of hydrology and reservoir operations.

The rest of this paper is organized as follows. Section 2 describes the methodology to generate continuous daily and 
embedded hourly rainfall for regular wet days and severe storms. Section 3 then describes the study area, selection of essential variables for the weather generation model and formulation of the observed data as well as the simulation rules. Next, section 4 discusses the above results. Conclusions are drawn in section 5 , along with recommendations for future research.

\section{METHODOLOGY}

The proposed continuous weather generator $(\mathrm{CWG})$ is based on the works of Richardson (1981) and Pickering et al. (1988). However, this work focuses only on generating daily rainfall and hourly rainfall for regular wet days and severe storms, respectively. Figure 1 shows the generation procedure. The generator first produces a wet day or dry day event based on conditional wet day probability. If it is a wet day, a random number is generated to compare with the probability of severe storms in order to determine whether it is a regular rainfall event or a severe storm. If it is a severe storm, hourly rainfall is generated for the day. The amount of daily rainfall for regular wet days and severe storms is generated based on different distributions. If it is a severe

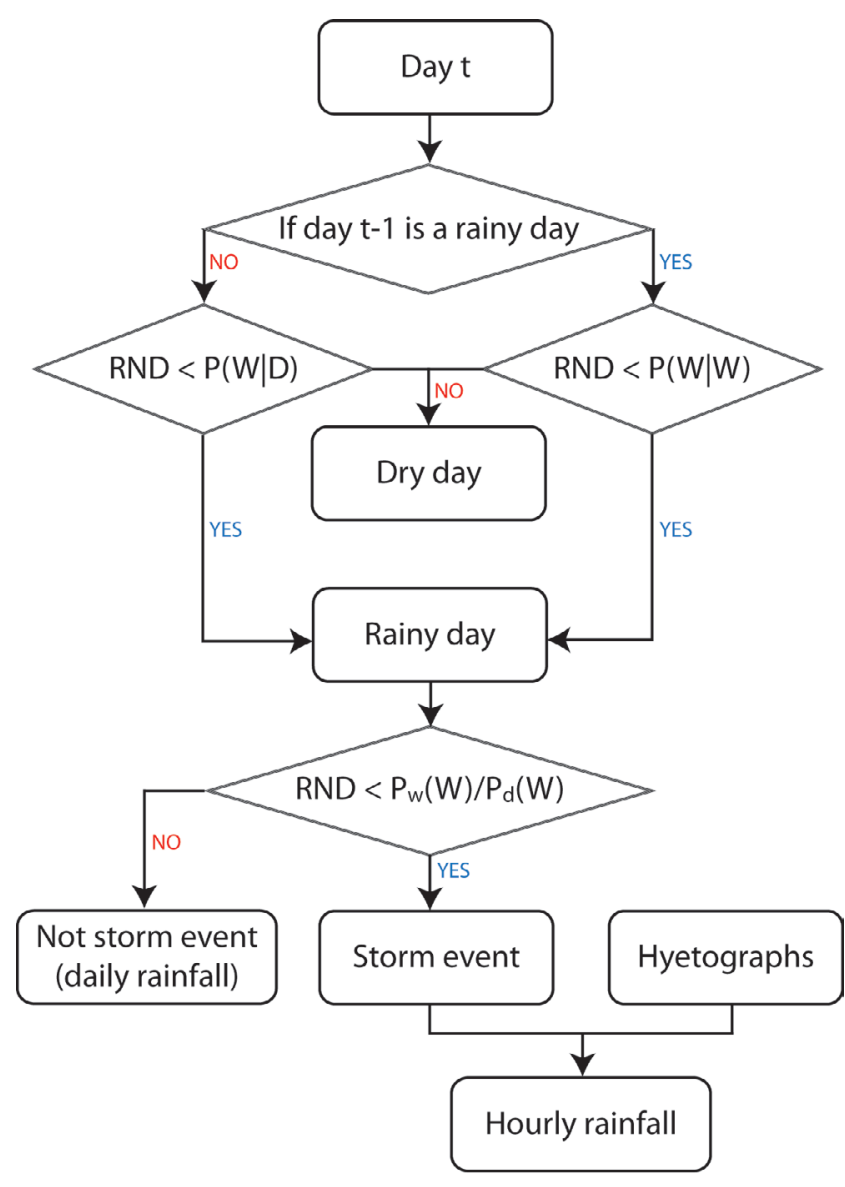

Fig. 1. Flow chart of continuous rainfall generation. storm, the daily rainfall is further allocated to 24 hours based on generated hyetograph. The following sections describe the proposed weather generator in detail.

\subsection{Wet Day Event}

Wet day event generation is described first. The criterion to generate a wet or dry day is established by comparing a uniformly distributed random number with conditional probabilities $\mathrm{P}(\mathrm{W} \mid \mathrm{W})$ and $\mathrm{P}(\mathrm{WID})$, which is the same as Richardson's method (1981). A wet day is generated if the criterion, as shown in Eq. (1), is fulfilled.

$\varepsilon \leq \begin{cases}\mathrm{P}_{\mathrm{m}}(\mathrm{W} \mid \mathrm{W}) & \text { if previous day is a wet day } \\ \mathrm{P}_{\mathrm{m}}(\mathrm{W} \mid \mathrm{D}) & \text { if previous day is a dry day }\end{cases}$

where $\varepsilon$ denotes a uniformly distributed random number; $\mathrm{P}_{\mathrm{m}}(\mathrm{W} / \mathrm{W})$ represents the probability of a wet day on day $\mathrm{t}$ given a wet day on previous day $t-1$; and $\mathrm{P}_{\mathrm{m}}(\mathrm{WID})$ refers the probability of a wet day on day $t$, given a dry day on previous day $\mathrm{t}-1 . \mathrm{P}_{\mathrm{m}}(\mathrm{W} \mid \mathrm{W})$ and $\mathrm{P}_{\mathrm{m}}(\mathrm{W} \mid \mathrm{D})$ can be calculated based on historical rainfall data for each month, respectively. Additionally, the wet day event on the first day for each month is determined based on the unconditional wet day probability $\mathrm{P}_{\mathrm{m}}(\mathrm{W})$ for each month.

If it is a wet day, whether or not it has a severe storm must also be determined. Thus, another uniformly distributed random number is generated to compare with the probability of severe storm, as shown in Eq. (2).

$\varepsilon \leq \begin{cases}\mathrm{P}_{\mathrm{w}}(\mathrm{S}) & \text { for wet season } \\ \mathrm{P}_{\mathrm{d}}(\mathrm{S}) & \text { for dry season }\end{cases}$

where $P_{w}(S)$ and $P_{d}(S)$ denote the probabilities of severe storm for wet and dry seasons, respectively. A severe storm is defined as daily rainfall more than 130 millimeters, according to the definition of the Central Weather Bureau of Taiwan. Owing to insufficient storm events for each month, the probability is determined for wet (May through October) and dry (November through next year April) seasons only. The threshold to determine severe storms and seasons may differ in different locations. If it is a wet day, a certain amount of daily rainfall is generated based on different distributions for a regular wet day and a severe storm. For a severe storm, daily rainfall is further allocated to each hour, based on a hyetograph generation. The following section describes how to generate rainfall amount and hyetograph.

\subsection{Rainfall Amount}

The rainfall amount is generated by the inverse function of rainfall cumulative distribution function. Additionally, 
the amounts of rainfall for a regular wet day and a severe storm are generated from different distributions. The rainfall distribution of regular wet days is assumed here to be exponential distribution or Weibull distribution. Meanwhile, the rainfall distribution of severe storms could be Pearson type III distribution (PT3) or Log Pearson type III distribution (LPT3). Although the distribution function is assumed to be the same for each month, the parameters used in the distribution differ from each other and are calculated based on the historical rainfall data for each month.

The cumulative distribution functions (CDF) of exponential distribution and Weibull distribution are given in Eqs. (3) and (4).

$\mathrm{F}\left(\mathrm{x} ; \lambda_{1}\right)=1-\mathrm{e}^{-\lambda_{1} \mathrm{x}}$

$\mathrm{F}\left(\mathrm{x} ; \lambda_{2}, \mathrm{k}\right)=1-\mathrm{e}^{-\left(\mathrm{x} / \mathrm{z}_{2}\right)^{k}}$

where $\lambda_{1}$ is average rainfall; $\lambda_{2}$ is the scale parameter and $\mathrm{k}$ is the shape parameter of the distribution. The daily rainfall can be generated with the inverse CDF of exponential distribution as shown in Eq. (5) or Weibull distribution as shown in Eq. (6). The inverse CDF of Weibull distribution is based on the single-parameter Weibull distribution estimated by Selker and Haith (1990).

$\mathrm{P}=\lambda_{\mathrm{m}} \times[-\ln (1-\mathrm{RND})]$

$\mathrm{P}=\left\{\lambda_{\mathrm{m}} \times[-\ln (1-\mathrm{RND})]^{0.75}\right\} / 1.191$

where $\mathrm{P}$ is the rainfall amount for a wet day, and $\lambda_{\mathrm{m}}$ is the average rainfall of wet day in month $\mathrm{m}$. RND, the uniformly distributed random variable in $(0,1)$, is defined as the rainfall probability. With these two inverse equations, the daily rainfall amount of a regular wet day can be generated.

The distribution of extreme events is often assumed to be a Pearson type III distribution (PT3) or Log Pearson type III distribution (LPT3). Heavy seasonal rainfall in June and typhoons bring heavy rainfall to Taiwan every year. Without generating severe storm rainfall properly, rainfall characteristics are not reproduced realistically. This work selects the PT3 distribution and LPT3 distribution as candidates to generate storm rainfall.

When PT3 is used to generate rainfall the relationship between generated rainfall and frequency index $\left(\mathrm{K}_{\mathrm{T}}\right)$ can be expressed as Eq. (7).

$\mathrm{X}_{\mathrm{t}}=\overline{\mathrm{X}}_{\mathrm{m}}+\mathrm{K}_{\mathrm{T}} \mathrm{S}$ where $X_{t}$ is the daily rainfall amount; $\bar{X}_{m}$ represents the mean rainfall of month $\mathrm{m}$; and $\mathrm{S}$ is the standard deviation. The frequency index $\left(\mathrm{K}_{\mathrm{T}}\right)$ is calculated based on coefficient of skewness $\left(\mathrm{C}_{\mathrm{s}}\right)$, the standard normal value and the exceedance probability. While LPT3 is used to generate rainfall, the relationship between estimated rainfall and frequency index is the same. However, $\overline{\mathrm{X}}_{\mathrm{m}}, \mathrm{S}$, and $\mathrm{C}_{\mathrm{s}}$ denote the mean, standard deviation and coefficient of skewness of the values of the logarithms of data, respectively.

\subsection{Hyetograph}

If it is a severe storm, daily rainfall amount is further allocated to each hour based on a generated hyetograph. Several methods have been developed to describe the temporal distribution of rainfall for severe storms (Huff 1967; Yen and Chow 1980; Pilgrim and Codery 1975; Koutsoyiannis and Foufoula-Georgiou 1993; Cheng et al. 2001). Eagleson (1970) noted that considerable evidence suggests that for given climatic conditions, events of a given scale exhibit quite similar distributions when normalized with respect to size and duration. According to that work, convective and frontal storms tend to have their peak rates near the beginning of rainfall. Meanwhile, cyclonic events have peak rainfall somewhere near the central of the storm duration. Therefore, this work adopts the Huff method (Huff 1967) to classify rainfall into 4 types. The storms are classified into four groups, depending on whether peak rainfall occurs in the first, second, third, or fourth quarter of the storm period. The percentage of rainfall during each hour can be calculated for different groups. The shape functions and occurrence probabilities of the four patterns can be estimated from historical weather data.

When a severe storm event is generated, a uniformly distributed random number is sampled to generate a hyetograph, as shown in Eq. (8)

$\mathrm{K}=\left\{\begin{array}{l}1 \text { if } \varepsilon \leq \mathrm{P}_{\mathrm{w}}(1) \\ \operatorname{Min}_{2 \leq \mathrm{K} \leq 4}\left\{\sum_{\mathrm{i}=1}^{\mathrm{K}-1} \mathrm{P}_{\mathrm{w}}(\mathrm{i}) \leq \varepsilon<\sum_{\mathrm{i}=1}^{\mathrm{K}} \mathrm{P}_{\mathrm{w}}(\mathrm{i})\right\}\end{array}\right.$

where $\mathrm{K}$ is the generated severe storm pattern; $\mathrm{P}_{\mathrm{w}}(\mathrm{i})$ is the probability of pattern $\mathrm{i}$ for the wet season; and $\mathrm{i}=1,2,3$, 4. If a severe storm is generated for dry seasons, $P_{w}(i)$ is replaced with $\mathrm{P}_{\mathrm{d}}(\mathrm{i})$. After the severe storm pattern $\mathrm{K}$ is generated, the hourly rainfall is expressed as Eq. (9).

$\mathrm{X}_{\mathrm{t}, \mathrm{h}}=\mathrm{p}_{\mathrm{k}, \mathrm{h}} \mathrm{X}_{\mathrm{t}}$ for $\mathrm{h}=1,2, \ldots, 24$

where $\mathrm{X}_{\mathrm{t}, \mathrm{h}}$ is hourly rainfall of day $\mathrm{t}$; $\mathrm{X}_{\mathrm{t}}$ is total daily rainfall generated by Eq. (7); and $p_{k, h}$ is rainfall percentage of $h$ hour of pattern $\mathrm{k}$, respectively. 


\section{RESULTS}

The proposed weather generator is applied to two study areas, Shihmen reservoir and Tsengwen reservoir watersheds, in Taiwan. The following subsections describe the study areas and results with respect to generating daily and embedded hourly rainfall data.

\subsection{Study Area}

Because the tropic of Cancer passes through Central Taiwan, weather patterns in northern and southern Taiwan markedly differ from each other. Northern and southern Taiwan are subtropical and tropical climates, respectively. This work evaluates the applicability of the proposed rainfall generator by selecting the Shayun rain gauge located in the Shihmen reservoir watershed and the Tsengwen rain gauge in the Tsengwen reservoir watershed as case studies. Shihmen reservoir is a vital water supply for northern Taiwan. Total area of the Shihmen reservoir watershed is approximately 763 square kilometers. The mean monthly temperature is around 12 to $26^{\circ} \mathrm{C}$, and the average annual temperature is about $20^{\circ} \mathrm{C}$. Annual rainfall is about $2800 \mathrm{~mm}$, and nearly $74 \%$ of annual rainfall occurs in the wet season (May through October). However, the Tsengwen rain gauge is in the Tsengwen reservoir watershed, located in the upstream of Tsengwen River (Fig. 2). As the largest reservoir in Taiwan, Tsengwen reservoir is the most important reservoir in southern Taiwan. Although annual temperature of Tsengwen reservoir watershed is around $24.6^{\circ} \mathrm{C}$, more than $80 \%$ of the days during the wet season has a maximum temperature exceeding $30^{\circ} \mathrm{C}$. Even over $40 \%$ of the days in March, April and November have a daily maximum temperature higher than $30^{\circ} \mathrm{C}$. Annual rainfall in this area is approximately $2900 \mathrm{~mm}$, and $90 \%$ of the rainfall occurs during the wet season. According to recorded weather data, the Tsengwen Reservoir watershed has a high temperature, few wet days, and high rainfall intensity.

\subsection{Rainfall Generation}

Rainfall is separated into regular rainfall and severe storms with the threshold of $130 \mathrm{~mm}$ daily rainfall. The rainfall data used in this study for the Shayun and Tsengwen rain gauge stations are from 1968 to 2008 and 1975 to 2010, respectively. In the proposed CWG model, exponential distribution and Weibull distribution are candidates for reproducing regular daily rainfall, while the PT3 distribution and LPT3 distribution are candidates to generate daily rainfall for severe storms. Proper distributions are selected using the

\section{Shihmen Reservoir watershed}

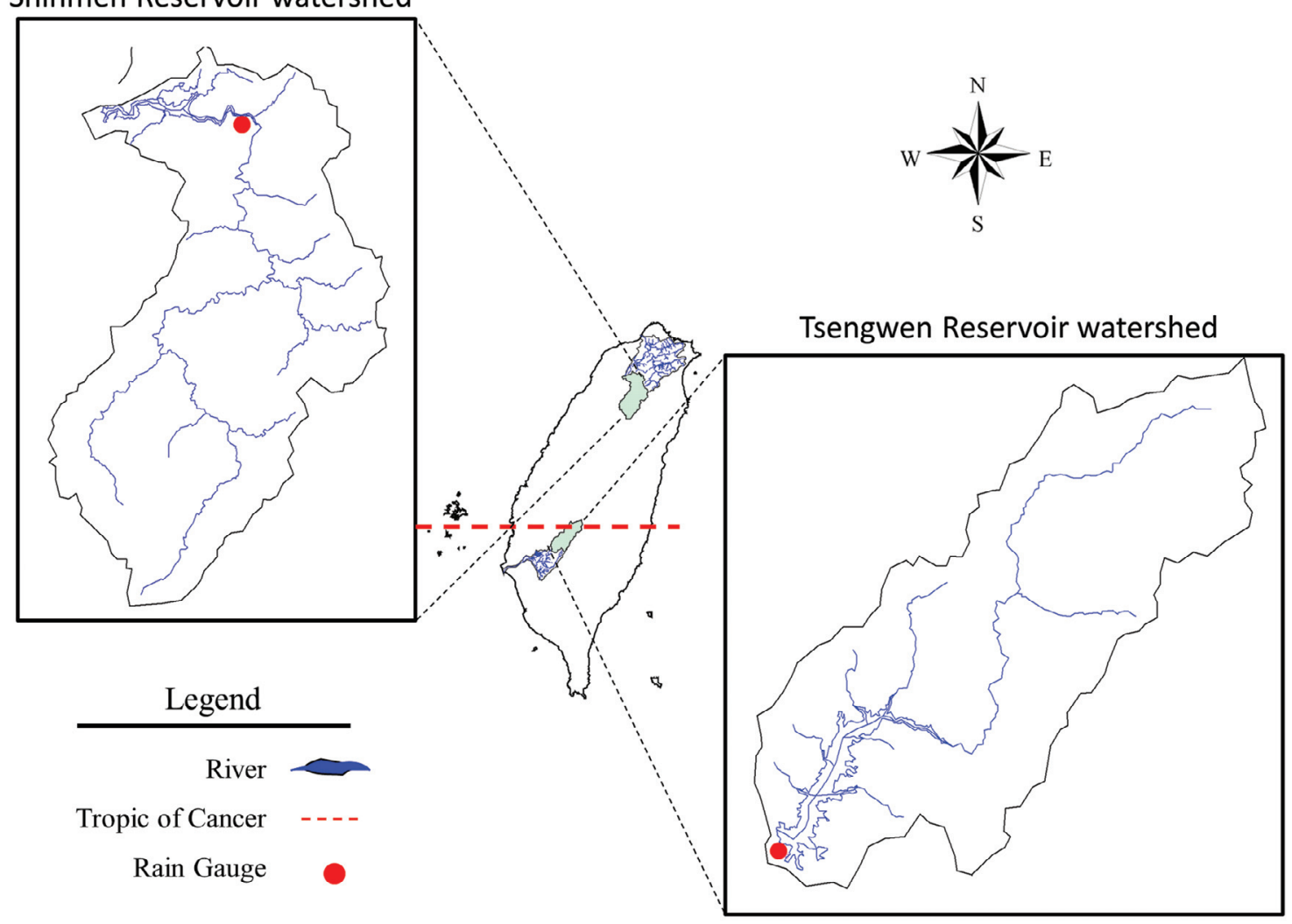

Fig. 2. The locations of the two study watersheds and rain gauges. 
goodness of fit (GOF) test. This section discusses the performance of generating wet day probability, daily rainfall, and hourly rainfall.

\subsubsection{Wet Day Probability}

Reproducing wet day probabilities performance is examined. Table 1 lists the historical and generated unconditional wet day probability $\mathrm{P}(\mathrm{W})$ and conditional wet day probability $\mathrm{P}(\mathrm{W} \mid \mathrm{W})$ and $\mathrm{P}(\mathrm{WID})$. While generating the rainfall data, whether or not the first day of each month is a wet day using $\mathrm{P}(\mathrm{W})$. The monthly $\mathrm{P}(\mathrm{W})$ of the Shayun rain gauge ranges from 0.23 to 0.52 (Table 1). Notably, $\mathrm{P}(\mathrm{W})$ during the wet season is slightly higher than during the dry season. As mentioned earlier, $90 \%$ of the rainfall in the Tsengwen reservoir watershed occurs during the wet season. This explains why the wet day probability during the wet season is significantly higher than during the dry season. Additionally, $\mathrm{P}(\mathrm{W})$ ranges from 0.15 to 0.66 during the wet season and from 0.09 to 0.24 during the dry season, respectively. In particular, $\mathrm{P}(\mathrm{W})$ of November and December is only 0.09 .

$\mathrm{P}(\mathrm{WID})$ is the probability of a wet day given that the previous day is a dry day. A lower $\mathrm{P}(\mathrm{WID})$ implies more difficulty in changing to a wet day if the previous day is a dry one. Therefore, while $\mathrm{P}(\mathrm{WID})$ is lower, the corresponding $\mathrm{P}(\mathrm{W})$ is lower. The most obvious example is Tsengwen, in which the $\mathrm{P}(\mathrm{WID})$ values in November and December are only 0.06 , and the corresponding $\mathrm{P}(\mathrm{W})$ is only 0.09 . $\mathrm{P}(\mathrm{WIW})$ is the probability of rainfall for two consecutive days. In both Shayun and in Tsengwen the probability of rainfall for two consecutive days exceeds $40 \%$. Additionally, $\mathrm{P}(\mathrm{WIW})$ for the two areas exceeds $50 \%$ during the wet season.

Table 1 indicates that the generated $\mathrm{P}(\mathrm{W}), \mathrm{P}(\mathrm{WID})$ and $\mathrm{P}(\mathrm{WIW})$ are the same or only slightly differ from historical data for each month. The generated monthly trends are the same as the historical ones, indicating that the seasonality and daily variation of rainfall can be reproduced properly by the proposed CWG model.

\subsubsection{Daily Rainfall for Regular Wet Days}

The rainfall cumulative distribution function profoundly plays a key role in the amount of rainfall generated. Before the CWG model is applied, daily rainfall data for each month are used to undertake the GOF test for each month. The distribution deemed appropriate for the most months is selected. Notably, the statistical parameters of the distributions (e.g., monthly mean wet day rainfall) differ for each month. Table 2 summarizes the GOF test results and the used parameters for each month.

According to the GOF test results, the Weibull distribution passes the test for all months and is subsequently used for the Shayun rain gauge. The Weibull distribution fits well in the months having lower rainfall, such as January and February. In January, the Weibull distribution reproduces the rainfall data close to the historical data (Fig. 3a). In those months with higher rainfall, some errors occur between generated rainfall and historical rainfall. For instance, in July, the application of Weibull distribution slightly overestimates the rainfall, which is less than $10 \mathrm{~mm}$ and little underestimates the rainfall ranging from 20 to $80 \mathrm{~mm}$. Analysis results indicate that, except of December, the Weibull distribution tends to perform better in terms of rainfall reproduction of the dry season for the Shayun rain gauge as shown in Table 3.

Both the Exponential distribution and Weibull distribution do not pass the GOF test for all months of the Tsengwen rain gauge. The distribution to have more months passing the GOF test is selected. Thus, the Weibull distribution is used for the Tsengwen rain gauge. Similar to the application to the Shayun rain gauge, the errors between generated and observed rainfall data are negligible in January. However, in July, although the generated rainfall between 20 to $80 \mathrm{~mm}$ is slightly underestimated, the errors are less than $8 \mathrm{~mm}$. The above results are also reflected in the monthly rainfall. The generated and historical rainfall errors are greater during the wet season than during the dry season (Fig. 3b and Table 3).

Historical rainfall data are compared with corresponding generated rainfall data, which have the same cumulative probability. The root mean square error (RMSE) of Shayun and Tsengwen are $12.8 \mathrm{~mm}(0.6 \%)$ and $26.8 \mathrm{~mm}(1.3 \%)$, respectively. The Nash-Sutcliffe efficiency coefficients are 0.98 and 0.97 in Shayun and Tsengwen, respectively. The above results further indicate that regular daily rainfall can be reproduced reasonably by the CWG model for the two study rain gauges.

\subsection{Hourly Rainfall Generation for Severe Storms}

A severe storm is defined here as daily rainfall exceeding $130 \mathrm{~mm}$; in addition, hourly rainfall is required. The PT3 and LPT3 distributions are examined using the GOF test to identify the appropriate distribution for the study areas. Due to limited data, all storm events are tested together. Notably, only LPT3 passes the test for the Shayun station, while both PT3 and LPT3 pass the test for the Tsengwen station. Thus, LPT3 and PT3 are selected for the Shayun and Tsengwen stations, respectively. Figures $4 \mathrm{a}$ and $\mathrm{b}$ compare the generated and historical distributions for the two study areas. The historical distribution here is an empirical distribution based on historical rainfall data.

Although the amount of severe storm data in both stations is for more than 100 days, the historical rainfall probability distribution of the two stations is unlikely to perfectly fit the selected distributions. Although LPT3 passes the GOF test, Fig. 4a indicates that LPT3 may underestimate 
rainfall for cumulative probabilities in the range of 0.7 to 0.9 for the Shayun station. Meanwhile, according to Fig. $4 \mathrm{~b}$, PT3 may underestimate rainfall for cumulative probabilities ranging from 0.8 to 0.9 for the Tsengwen station. The errors between the historical and generated heavy rainfall can thus be expected. The average severe storm rainfall of historical and generated is 237 and $230 \mathrm{~mm}$ in Shayun and 230 and
$240.6 \mathrm{~mm}$ in Tsengwen, respectively.

The hyetography is assumed to last only 24 hours. A future study should improve this work to generate different rainfall durations. The hyetographs for two study areas are also analyzed in the CWG model. According to the Huff method, the hyetograph in each study area is classified into four categories, followed by estimation of average rainfall

Table 1. Historical and generated wet day probability of Shayun and Tsengwen rain gauges.

\begin{tabular}{|c|c|c|c|c|c|c|c|c|c|c|c|c|}
\hline \multirow{3}{*}{ Month } & \multicolumn{6}{|c|}{ Shayun } & \multicolumn{6}{|c|}{ Tsengwen } \\
\hline & \multicolumn{2}{|c|}{$\mathbf{P}(\mathbf{W})$} & \multicolumn{2}{|c|}{$\mathbf{P}(\mathbf{W} \mid \mathrm{D})$} & \multicolumn{2}{|c|}{$\mathbf{P}(\mathbf{W} \mid \mathbf{W})$} & \multicolumn{2}{|c|}{$\mathbf{P}(\mathbf{W})$} & \multicolumn{2}{|c|}{$\mathbf{P}(\mathbf{W} \mid \mathrm{D})$} & \multicolumn{2}{|c|}{$\mathbf{P}(\mathbf{W} \mid W)$} \\
\hline & His & Gen & His & Gen & His & Gen & His & Gen & His & Gen & His & Gen \\
\hline 1 & 0.30 & 0.30 & 0.20 & 0.20 & 0.54 & 0.53 & 0.12 & 0.12 & 0.08 & 0.09 & 0.42 & 0.38 \\
\hline 2 & 0.40 & 0.40 & 0.22 & 0.23 & 0.67 & 0.66 & 0.17 & 0.17 & 0.11 & 0.11 & 0.49 & 0.47 \\
\hline 3 & 0.43 & 0.42 & 0.25 & 0.26 & 0.66 & 0.65 & 0.19 & 0.19 & 0.12 & 0.12 & 0.47 & 0.46 \\
\hline 4 & 0.43 & 0.42 & 0.30 & 0.30 & 0.60 & 0.59 & 0.24 & 0.24 & 0.16 & 0.16 & 0.50 & 0.48 \\
\hline 5 & 0.51 & 0.50 & 0.33 & 0.33 & 0.68 & 0.67 & 0.35 & 0.34 & 0.22 & 0.22 & 0.59 & 0.57 \\
\hline 6 & 0.52 & 0.52 & 0.31 & 0.32 & 0.71 & 0.71 & 0.53 & 0.52 & 0.32 & 0.31 & 0.72 & 0.71 \\
\hline 7 & 0.41 & 0.40 & 0.26 & 0.26 & 0.63 & 0.61 & 0.52 & 0.51 & 0.35 & 0.35 & 0.68 & 0.67 \\
\hline 8 & 0.45 & 0.45 & 0.29 & 0.30 & 0.64 & 0.63 & 0.66 & 0.66 & 0.46 & 0.47 & 0.76 & 0.76 \\
\hline 9 & 0.41 & 0.40 & 0.24 & 0.24 & 0.66 & 0.64 & 0.49 & 0.49 & 0.35 & 0.35 & 0.64 & 0.64 \\
\hline 10 & 0.23 & 0.22 & 0.12 & 0.13 & 0.57 & 0.54 & 0.15 & 0.15 & 0.10 & 0.10 & 0.43 & 0.41 \\
\hline 11 & 0.24 & 0.24 & 0.16 & 0.17 & 0.51 & 0.48 & 0.09 & 0.08 & 0.06 & 0.06 & 0.43 & 0.40 \\
\hline 12 & 0.23 & 0.22 & 0.16 & 0.16 & 0.46 & 0.43 & 0.09 & 0.09 & 0.06 & 0.06 & 0.40 & 0.39 \\
\hline
\end{tabular}

Table 2. The GOF test results for the Shayun and Tsengwen rain gauges.

\begin{tabular}{|c|c|c|c|c|c|c|}
\hline \multicolumn{7}{|c|}{ Severe Storm } \\
\hline \multirow{3}{*}{$\begin{array}{l}\text { Season } \\
\text { Wet/Dry }\end{array}$} & \multicolumn{3}{|c|}{ Shayun } & \multicolumn{3}{|c|}{ Tsengwen } \\
\hline & \multirow{2}{*}{$\begin{array}{l}\text { PT3 } \\
\text { No }\end{array}$} & \multirow{2}{*}{\multicolumn{2}{|c|}{$\begin{array}{c}\text { LPT3 } \\
\text { Yes }\end{array}$}} & \multirow{2}{*}{\multicolumn{2}{|c|}{$\begin{array}{l}\text { PT3 } \\
\text { Yes }\end{array}$}} & LPT3 \\
\hline & & & & & & Yes \\
\hline \multicolumn{7}{|c|}{ Regular Wet Day } \\
\hline \multirow[b]{2}{*}{ Month } & \multicolumn{3}{|c|}{ Shayun } & \multicolumn{3}{|c|}{ Tsengwen } \\
\hline & Exponential & Weibull & $\begin{array}{c}\text { Mean rainfall } \\
\left(\mathrm{mm} \text { day }^{-1}\right)\end{array}$ & Exponential & Weibull & $\begin{array}{c}\text { Mean rainfall } \\
\left(\mathrm{mm} \text { day }^{-1}\right)\end{array}$ \\
\hline January & Yes & Yes & 8.6 & Yes & Yes & 5.6 \\
\hline February & Yes & Yes & 13.8 & Yes & Yes & 7.7 \\
\hline March & Yes & Yes & 13.8 & Yes & Yes & 9.0 \\
\hline April & Yes & Yes & 14.0 & No & Yes & 12.5 \\
\hline May & No & Yes & 16.7 & Yes & Yes & 20.3 \\
\hline June & No & Yes & 21.8 & Yes & No & 25.1 \\
\hline July & No & Yes & 18.6 & No & Yes & 22.9 \\
\hline August & No & Yes & 20.9 & No & Yes & 25.7 \\
\hline September & No & Yes & 20.7 & No & Yes & 17.7 \\
\hline October & No & Yes & 15.1 & Yes & Yes & 12.9 \\
\hline November & Yes & Yes & 7.5 & Yes & Yes & 7.2 \\
\hline December & Yes & Yes & 8.5 & Yes & Yes & 5.4 \\
\hline
\end{tabular}



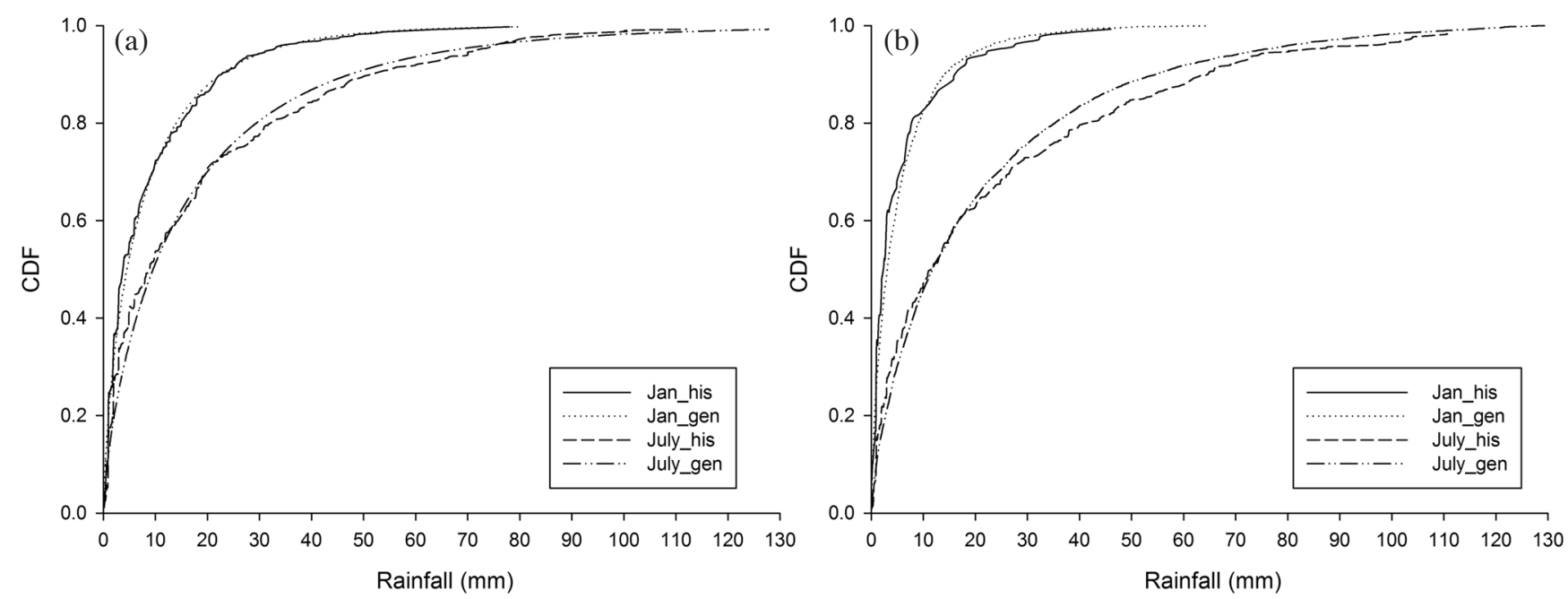

Fig. 3. Historical and generated distributions of regular rainfall for January and July (a) Shayun and (b) Tsengwen.

Table 3. Historical and generated monthly rainfall $(\mathrm{mm})$ for Shayun and Tsengwen.

\begin{tabular}{|c|ccc|ccc|}
\hline \multirow{2}{*}{ Month } & \multicolumn{3}{|c|}{ Shayun } & \multicolumn{3}{c|}{ Tsengwen } \\
\cline { 2 - 7 } & Historical & Generated & Error & Historical & Generated & Error \\
\hline 1 & 82.5 & 83.5 & $1.3 \%$ & 21.8 & 23.0 & $5.6 \%$ \\
2 & 153.7 & 150.9 & $-1.9 \%$ & 37.4 & 36.7 & $-2.1 \%$ \\
3 & 185.1 & 173.2 & $-6.4 \%$ & 52.9 & 50.7 & $-4.2 \%$ \\
4 & 177.4 & 168.3 & $-5.1 \%$ & 90.9 & 84.5 & $-7.1 \%$ \\
5 & 269.7 & 247.4 & $-8.3 \%$ & 216.2 & 189.3 & $-12.4 \%$ \\
6 & 330.3 & 305.1 & $-7.7 \%$ & 385.8 & 331.0 & $-14.2 \%$ \\
7 & 229.6 & 219.0 & $-4.6 \%$ & 351.4 & 320.2 & $-8.9 \%$ \\
8 & 274.4 & 257.3 & $-6.2 \%$ & 499.0 & 440.7 & $-11.7 \%$ \\
9 & 243.8 & 231.5 & $-5.1 \%$ & 253.0 & 231.3 & $-8.6 \%$ \\
10 & 98.2 & 96.8 & $-1.4 \%$ & 60.7 & 59.0 & $-2.7 \%$ \\
11 & 60.2 & 61.5 & $2.1 \%$ & 19.3 & 18.8 & $-2.6 \%$ \\
12 & 62.1 & 57.1 & $-8.1 \%$ & 15.1 & 14.9 & $-1.5 \%$ \\
\hline
\end{tabular}
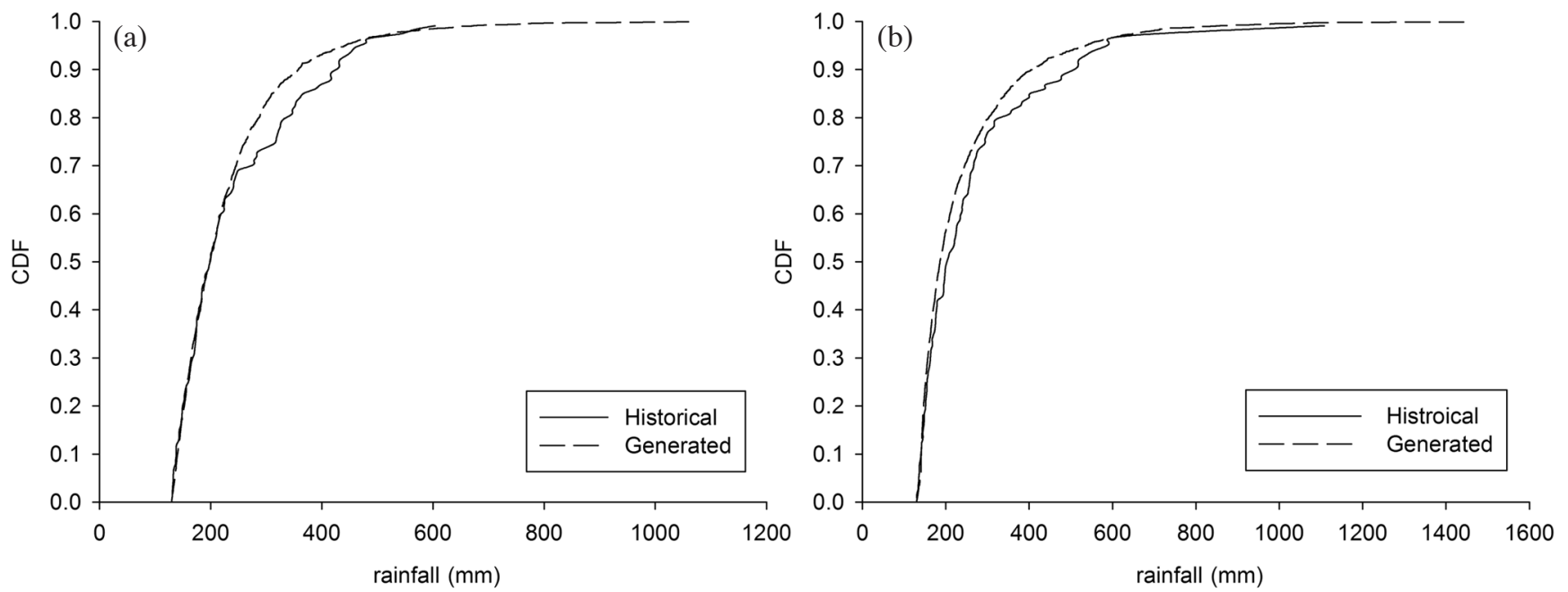

Fig. 4. Historical and generated distributions of severe storms (a) Shayun and (b) Tsengwen. 
percentages for each hour. Table 4 lists the rainfall percentages. According to this table, the hourly rainfall can be generated.

\section{DISCUSSION}

\subsection{Benefits of Separating Severe Storms from Regular Rainfall}

Conventionally, regular rainfall and severe storms are generated from the same distribution. In this work the rainfall data are separated into two groups and generated using two different distributions. The generated rainfall data in July of the Shayun station illustrates the benefits of using a different distribution for severe storms. Historical statistics are used first to reproduce rainfall data using the Weibull distribution for regular rainfall. Closely examining rainfall amounts less than $130 \mathrm{~mm}$ reveals that RMSE is only $3.9 \mathrm{~mm}$. If rainfall data are not classified into two categories and the Weibull distribution is used to generate all rainfall events, RMSEs are 5.8 and $14.7 \mathrm{~mm}$ for rainfall amount less than $130 \mathrm{~mm}$ and for all rainfall data, respectively. Further examining the generated rainfall over $130 \mathrm{~mm}$ reveals that RMSE is $115.3 \mathrm{~mm}$ using one distribution, while RMSE is only $22.0 \mathrm{~mm}$ using a different distribution for severe storms. The analysis results indicate that the Weibull distribution or a single distribution may not be able to generate rainfall amount for both regular rainfall and severe storms well. Rainfall data should thus be classified into different categories as well as data generated using different distributions.

\subsection{Threshold of Severe Storms}

Based on a threshold of $130 \mathrm{~mm}$, rainfall data are classified into regular rainfall and severe storm categories. Rainfall data are then generated for the two categories using two distributions. The performance of different thresholds is also considered and evaluated in this work. According to the storm rainfall definition provided by the Central Weather Bureau of Taiwan, accumulated rainfall in 24 hours over 50,130 , and $200 \mathrm{~mm}$ is called heavy rainfall, extremely heavy rainfall and torrential rainfall, respectively. Thus, the

Table 4. Rainfall percentage in each hour of 4 severe storm types.

\begin{tabular}{|c|cccc|cccc|}
\hline \multirow{2}{*}{ Hour } & \multicolumn{5}{|c}{ Shayun } & \multicolumn{4}{c|}{ Tsengwen } \\
\cline { 2 - 8 } & Type1 & Type2 & Type3 & Type4 & Type1 & Type2 & Type3 & Type4 \\
\hline 1 & 4.37 & 1.66 & 1.68 & 1.38 & 0.86 & 0.83 & 2.01 & 0.71 \\
2 & 10.16 & 1.47 & 2.11 & 1.28 & 2.06 & 1.61 & 1.72 & 4.12 \\
3 & 10.51 & 1.30 & 2.18 & 1.32 & 3.49 & 2.45 & 1.73 & 2.26 \\
4 & 7.75 & 2.23 & 2.68 & 1.70 & 6.56 & 3.93 & 2.15 & 2.24 \\
5 & 7.46 & 2.66 & 2.22 & 2.46 & 9.34 & 3.76 & 2.13 & 5.95 \\
6 & 7.40 & 3.34 & 2.48 & 2.53 & 10.42 & 5.46 & 2.37 & 5.19 \\
7 & 5.28 & 4.99 & 3.20 & 3.24 & 8.08 & 7.21 & 2.55 & 7.21 \\
8 & 3.29 & 6.47 & 3.54 & 2.56 & 5.33 & 7.98 & 3.23 & 7.32 \\
9 & 2.00 & 6.64 & 3.57 & 2.87 & 6.31 & 8.92 & 4.87 & 5.07 \\
10 & 2.75 & 6.75 & 4.24 & 2.75 & 3.64 & 8.90 & 5.70 & 6.06 \\
11 & 3.01 & 8.09 & 4.76 & 2.24 & 2.84 & 7.30 & 5.84 & 6.42 \\
12 & 3.27 & 10.98 & 5.28 & 3.70 & 3.57 & 6.59 & 8.65 & 4.24 \\
13 & 2.20 & 8.56 & 7.04 & 3.78 & 4.46 & 4.93 & 9.22 & 2.02 \\
14 & 2.35 & 4.26 & 8.08 & 3.90 & 3.34 & 4.18 & 7.92 & 1.76 \\
15 & 1.77 & 3.55 & 7.89 & 5.02 & 4.54 & 3.31 & 6.92 & 2.92 \\
16 & 3.47 & 3.95 & 7.64 & 5.43 & 2.53 & 2.53 & 6.66 & 3.42 \\
17 & 3.51 & 4.19 & 6.77 & 6.71 & 1.82 & 3.63 & 5.10 & 3.11 \\
18 & 3.20 & 4.40 & 6.31 & 7.42 & 3.34 & 3.62 & 3.59 & 5.29 \\
19 & 3.72 & 4.07 & 5.07 & 10.47 & 4.41 & 2.92 & 3.57 & 7.86 \\
20 & 3.76 & 3.14 & 3.90 & 9.15 & 3.58 & 2.46 & 3.90 & 9.12 \\
21 & 3.02 & 2.46 & 3.37 & 7.34 & 3.59 & 2.62 & 4.03 & 4.42 \\
23 & 3.21 & 2.25 & 2.83 & 7.35 & 2.95 & 2.16 & 2.77 & 1.24 \\
& 1.62 & 1.35 & 1.83 & 3.74 & 1.35 & 1.85 & 1.89 & 1.07 \\
& 0.95 & 1.26 & 1.34 & 1.68 & 1.62 & 0.86 & 1.48 & 0.98 \\
\hline
\end{tabular}


thresholds of 50, 130, and $200 \mathrm{~mm}$ are tested and evaluated. The CWG model can reproduce weather data well for the regular rainfall category, regardless of which threshold is selected. Therefore, this section discusses how different thresholds affect the ability to generate severe storms by examining the GOF test.

A higher rainfall threshold (i.e., $200 \mathrm{~mm} \mathrm{day}^{-1}$ ) results in less rainfall data in the severe storm category, making it difficult to identify a proper distribution. However, although a lower rainfall threshold (i.e., $50 \mathrm{~mm} \mathrm{day}^{-1}$ ) has more data in the severe storm category; neither PT3 nor LPT3 can pass the GOF test. As mentioned earlier, the rainfall threshold of $130 \mathrm{~mm}$ can result in adequate generation for the severe storm categories. The threshold is thus proper for the two study areas in Taiwan. However, the threshold may vary for different locations and, therefore, must be examined.

\subsection{Length of Generation}

The CWG model requires, at most, two more random numbers to generate a rainfall event than conventional weather generators. One random number is used to determine whether it is a severe storm, while the other number is used to select the hyetograph type. Thus, the different lengths of generation are tested to determine whether the CWG model requires generating more years to hold weather statistics. In this work, lengths of 10, 30, 50, 100, and 500 years are generated for the Shayun station. The statistics of different generation lengths are analyzed as follows.

A shorter generation length results in larger mean monthly rainfall errors between the historical and generated data, as shown in Table 5. The error in November reaches $50 \%$ while the generation length is only 10 years. Table 5 reveals that increasing the generation length gradually re-

Table 5. The monthly rainfall data errors for different simulation years.

\begin{tabular}{|c|rrrrr|}
\hline Month & 10 years & $\mathbf{3 0}$ years & $\mathbf{5 0}$ years & 100 years & $\mathbf{5 0 0}$ years \\
\hline 1 & $14.9 \%$ & $11.6 \%$ & $-5.1 \%$ & $-4.8 \%$ & $0.5 \%$ \\
2 & $-12.6 \%$ & $-8.9 \%$ & $15.4 \%$ & $0.6 \%$ & $-2.7 \%$ \\
3 & $-30.2 \%$ & $18.2 \%$ & $4.0 \%$ & $2.6 \%$ & $-5.8 \%$ \\
4 & $-2.2 \%$ & $-3.1 \%$ & $-8.8 \%$ & $-2.9 \%$ & $-5.4 \%$ \\
5 & $-0.1 \%$ & $-3.7 \%$ & $-14.3 \%$ & $-7.3 \%$ & $-7.0 \%$ \\
6 & $-18.1 \%$ & $-9.9 \%$ & $-12.6 \%$ & $-10.3 \%$ & $-7.6 \%$ \\
7 & $3.7 \%$ & $-17.7 \%$ & $-19.1 \%$ & $-4.7 \%$ & $-4.4 \%$ \\
8 & $-12.8 \%$ & $1.8 \%$ & $-5.9 \%$ & $-8.0 \%$ & $-7.6 \%$ \\
9 & $-10.3 \%$ & $-31.0 \%$ & $-10.2 \%$ & $-8.4 \%$ & $-3.6 \%$ \\
10 & $21.8 \%$ & $5.6 \%$ & $5.3 \%$ & $-4.0 \%$ & $-3.6 \%$ \\
11 & $47.8 \%$ & $-14.1 \%$ & $-2.4 \%$ & $-2.8 \%$ & $8.4 \%$ \\
12 & $-16.5 \%$ & $-15.6 \%$ & $1.4 \%$ & $6.5 \%$ & $-8.3 \%$ \\
\hline Average & $\mathbf{1 5 . 9 \%}$ & $\mathbf{1 1 . 8 \%}$ & $\mathbf{8 . 7 \%}$ & $\mathbf{5 . 2 \%}$ & $\mathbf{5 . 4 \%}$ \\
\hline
\end{tabular}

duces the error. Notably, the error for each month is less than $10 \%$, while the generation length is 500 years. Additionally, RMSE of 10-year generation is $29.5 \mathrm{~mm}$, and RMSE of 500-year generation decreases to $12.5 \mathrm{~mm}$. A longer generation length implies a more accurate reproduction of rainfall statistics. Table 5 further demonstrates that the 100 -year generation may be sufficient to reproduce statistics reasonably.

Historical and generated wet day probabilities differ by less than $4 \%$ in each month in the 500-year data (Table 6). Moreover, historical and generated $\mathrm{P}(\mathrm{W})$ and $\mathrm{P}(\mathrm{WID})$ differ by less than $1 \%$ for each month. However, the maximal difference reaches $10 \%$ in the 10 -year data. In most of the months, the difference between historical and generated wet day probabilities is higher than that of 500-year data. This finding suggests that longer data implies a closer proximity of the statistical properties to the historical data. However, Table 6 also shows that 100-year generation may reproduce wet day probabilities as well as 500 -year generation.

\subsection{Comparison of the Proposed CWG Model with LARS-WG Model}

The proposed CWG model is compared with the LARSWG model. The LARS-WG model is a mature and widely implemented weather generation model. In this work, this model is applied to generate 500-year rainfall data for the Shayun rain gauge station, followed by a comparison of that data with those generated by the CWG model. To compare the results of the two models, this subsection discusses the rainfall probabilities, rainfall amount, and maximum rainfall of storms.

Table 7 lists the difference in wet day probabilities between the historical and generated data from the CWG model and the LARS-WG model. The average errors of $\mathrm{P}(\mathrm{W})$, $\mathrm{P}(\mathrm{W} \mid \mathrm{D}), \mathrm{P}(\mathrm{WIW})$ using the CWG model are $2.5,1.9$, and $2.7 \%$, while those errors using the LARS-WG model are $5.1,6.8$, and $5.6 \%$, respectively. The CWG model generates rainfall events based on rainfall probabilities, thus performing better in terms of reproducing these probabilities. Table 8 lists average annual, wet season, dry season, and maximal rainfall amounts. The errors of annual rainfall for the CWG and LARS-WG models are only 1.6 and $2.2 \%$, respectively. The CWG model provides slightly better generations for annual and dry season rainfall than the LARS-WG model. The generated annual and wet/dry season rainfall is all close to observed weather data. Both the CWG and the LARS-WG model can reproduce historical statistics accurately.

Calculations are made of the mean wet day rainfall of those, which are lower than $130 \mathrm{~mm}$ for each month. RMSEs of the CWG model during the wet season, dry season, and the entire year are $1.36 \mathrm{~mm}(6.2 \%), 0.20 \mathrm{~mm}(1.6 \%)$, and $0.97 \mathrm{~mm}$ (3.9\%); meanwhile, RMSEs of the LARS-WG 
model are $0.85 \mathrm{~mm}(4.1 \%), 1.04 \mathrm{~mm}(7.7 \%)$, and $0.95 \mathrm{~mm}$ (5.9\%). Notably, the CWG model performs better during the dry season and similar outcomes as the LARS-WG model in wet season and annual rainfall generation.

Owing to its ability to generate rainfall based on the semi-empirical distribution, the LARS-WG model can reproduce historical distribution. The generated maximal rainfall from the LARS-WG model is $601 \mathrm{~mm}$ (Table 8), which is very close to the observed maximal rainfall, 605 mm among year 1968 through 2008. Possibly severe rainfall events that have not yet been observed can be generated from the LPT3 distribution. Among 500-year genera- tion, the generated maximal rainfall is $1060 \mathrm{~mm}$ (Table 8), which is significantly larger than the observed maximum. To generate rainfall for severe storms under climate change scenarios the CWG model can generate possible extreme events, while the LARS-WG model may underestimate possible future extreme events.

\section{CONCLUSIONS}

A weather generator often produces weather data based on weather statistics. Conventional weather generators reproduce data from a single distribution function and can only

Table 6 . The wet day probability errors for different simulation years.

\begin{tabular}{|c|c|c|c|c|c|c|c|c|c|c|c|c|c|c|c|}
\hline & \multicolumn{5}{|c|}{$\mathbf{P}(W)$} & \multicolumn{5}{|c|}{$\mathbf{P}(\mathbf{W I D})$} & \multicolumn{5}{|c|}{$\mathbf{P}(\mathbf{W} \mid \mathbf{W})$} \\
\hline Month & 10 & 30 & 50 & 100 & 500 & 10 & 30 & 50 & 100 & 500 & 10 & 30 & 50 & 100 & 500 \\
\hline 1 & 0.00 & 0.02 & -0.02 & -0.01 & 0.00 & -0.02 & 0.01 & -0.02 & -0.01 & 0.00 & 0.04 & 0.02 & -0.02 & 0.00 & -0.02 \\
\hline 2 & -0.04 & -0.02 & 0.05 & 0.00 & 0.00 & 0.00 & 0.02 & 0.04 & 0.00 & 0.01 & -0.07 & -0.05 & 0.01 & 0.00 & -0.01 \\
\hline 3 & -0.07 & 0.04 & -0.01 & 0.00 & -0.01 & -0.01 & 0.04 & 0.02 & 0.01 & 0.01 & -0.09 & 0.00 & -0.04 & -0.01 & -0.02 \\
\hline 4 & 0.02 & -0.02 & -0.03 & -0.02 & -0.01 & 0.00 & -0.03 & 0.00 & 0.00 & 0.00 & 0.03 & 0.01 & -0.04 & -0.02 & -0.01 \\
\hline 5 & 0.05 & 0.01 & -0.03 & 0.01 & 0.00 & 0.08 & 0.01 & -0.02 & 0.01 & 0.01 & -0.01 & 0.01 & -0.02 & 0.00 & -0.01 \\
\hline 6 & -0.03 & 0.00 & -0.02 & -0.01 & 0.00 & 0.02 & 0.00 & -0.01 & 0.00 & 0.01 & -0.05 & 0.01 & -0.01 & 0.00 & 0.00 \\
\hline 7 & -0.06 & -0.01 & -0.04 & 0.00 & -0.01 & -0.02 & 0.00 & -0.02 & 0.00 & 0.00 & -0.08 & -0.02 & -0.04 & -0.01 & -0.02 \\
\hline 8 & -0.08 & 0.01 & 0.04 & 0.00 & 0.00 & -0.06 & 0.03 & 0.05 & 0.01 & 0.01 & -0.03 & -0.01 & 0.00 & -0.02 & -0.01 \\
\hline 9 & -0.01 & -0.07 & -0.02 & -0.01 & -0.01 & 0.00 & -0.02 & 0.01 & 0.01 & 0.00 & -0.01 & -0.08 & -0.04 & -0.03 & -0.01 \\
\hline 10 & 0.00 & -0.02 & 0.01 & -0.01 & -0.01 & 0.00 & 0.00 & 0.01 & 0.00 & 0.00 & -0.01 & -0.05 & 0.00 & -0.05 & -0.03 \\
\hline 11 & 0.10 & 0.00 & -0.02 & 0.01 & 0.00 & 0.05 & 0.01 & -0.02 & 0.00 & 0.01 & 0.08 & -0.05 & -0.01 & 0.02 & -0.03 \\
\hline 12 & 0.03 & -0.01 & 0.00 & 0.00 & -0.01 & 0.04 & -0.01 & 0.01 & 0.01 & 0.00 & -0.03 & 0.01 & -0.05 & -0.03 & -0.04 \\
\hline
\end{tabular}

Table 7. The wet day probabilities for the historical data and generated weather data from the CWG model and the LARS-WG model.

\begin{tabular}{|c|ccc|ccc|ccc|}
\hline \multirow{2}{*}{ Month } & \multicolumn{3}{|c|}{ P(W) } & \multicolumn{3}{c|}{ P(WID) } & \multicolumn{3}{c|}{ P(WIW) } \\
\cline { 2 - 9 } & His & CWG & LARS & His & CWG & LARS & His & CWG & LARS \\
\hline 1 & 0.30 & 0.30 & 0.32 & 0.20 & 0.20 & 0.22 & 0.54 & 0.53 & 0.52 \\
2 & 0.40 & 0.40 & 0.40 & 0.22 & 0.23 & 0.22 & 0.67 & 0.66 & 0.67 \\
3 & 0.43 & 0.42 & 0.45 & 0.25 & 0.26 & 0.27 & 0.66 & 0.65 & 0.68 \\
4 & 0.43 & 0.42 & 0.45 & 0.30 & 0.30 & 0.31 & 0.60 & 0.59 & 0.62 \\
5 & 0.51 & 0.50 & 0.49 & 0.33 & 0.33 & 0.37 & 0.68 & 0.67 & 0.61 \\
6 & 0.52 & 0.52 & 0.50 & 0.31 & 0.32 & 0.30 & 0.71 & 0.71 & 0.70 \\
7 & 0.41 & 0.40 & 0.40 & 0.26 & 0.26 & 0.25 & 0.63 & 0.61 & 0.62 \\
8 & 0.45 & 0.45 & 0.39 & 0.29 & 0.30 & 0.28 & 0.64 & 0.63 & 0.56 \\
9 & 0.41 & 0.40 & 0.41 & 0.24 & 0.24 & 0.23 & 0.66 & 0.64 & 0.66 \\
10 & 0.23 & 0.22 & 0.21 & 0.12 & 0.13 & 0.13 & 0.57 & 0.54 & 0.51 \\
11 & 0.24 & 0.24 & 0.21 & 0.16 & 0.17 & 0.14 & 0.51 & 0.48 & 0.47 \\
12 & 0.23 & 0.22 & 0.23 & 0.16 & 0.16 & 0.18 & 0.46 & 0.43 & 0.40 \\
\hline
\end{tabular}


Table 8. Historical rainfall data and generated data from the CWG and LARS-WG model (unit: $\mathrm{mm}$ ).

\begin{tabular}{|c|ccc|}
\hline Rainfall & Historical & CWG & LARS \\
\hline Annual & 2831 & 2877 & 2892 \\
Wet season & $2092(73.9 \%)$ & $2139(74.3 \%)$ & $2079(71.9 \%)$ \\
Dry season & $738(26.1 \%)$ & $738(25.7 \%)$ & $814(28.1 \%)$ \\
Maximum & 604 & 1065 & 601 \\
\hline
\end{tabular}

generate the same temporal resolution data, such as daily temperature, rainfall, or solar radiation. Recent observations have identified more frequent and intensive flood and drought events in the recent decades. Additionally, serious flood and drought events may occur consecutively. Climate change may worsen this situation. Assessing the impacts of consecutive floods and droughts requires different temporal resolution weather data to conduct a continuous simulation. Thus, this work develops a continuous weather generation (CWG) model to produce daily rainfall for regular wet days and embedded hourly rainfall for days with severe storms. The CWG model was applied to two study areas to evaluate its performance. Simulation results indicate the proposed model can keep rainfall statistics and reproduce rainfall data reasonably. The CWG model was also compared with the widely used LARS-WG model. The analysis results indicate that the CWG model can provide daily rainfall data as reliably as the LARS-WG model can. Additionally, the CWG model can produce daily rainfall data with embedded hourly rainfall for those wet days with severe storm events. Moreover, the proposed model can generate more extreme events than the LARS-WG model can. The CWG model is applicable to climate change studies that evaluate the impacts of consecutive extreme flood and drought events.

The proposed CWG model adopts a threshold to divide rainfall data into two categories: regular rainfall and severe storms. The threshold of $130 \mathrm{~mm}$ is validated for the two study areas. However, the threshold may vary for different locations. Besides, two consecutive days having severe storms are treated as independent events in this study due to the limited number of consecutive severe storm events. However, the consecutive severe storm events require more attention in future studies. If there are many consecutive severe storm events, conditional probabilities or severe storm duration should be considered in the generation model. On the other hand, the proposed model requires two more random numbers to generate hourly rainfall data for each severe storm. If shorter data, such as 10-year or 30-year data, are generated, they may not be sufficient to keep rainfall statistics. Generating longer data is suggested and the length of 100 year may be sufficient. Finally, the proposed CWG model focused only on generating rainfall data for a single gauge station in this work. Future studies should examine the feasibility of generating other weather variables with embedded hourly data and generating areal weather data for a watershed. Efforts are underway to develop a hydrological model and reservoir operation model, which continuously run in daily and hourly time steps for regular wet days and severe storms. Importantly, the CWG model along with these simulation models is expected highly promising for use in climate change studies to assess the possible impacts of consecutive extreme weather and hydrological events in the future.

Acknowledgements The authors would like to thank the National Science Council of the Republic of China, Taiwan, for financially supporting this research under Contract No. NSC 98-2313-B-002-051-MY3.

\section{REFERENCES}

Araghinejad, S., 2011: An approach for probabilistic hydrological drought forecasting. Water Resour. Manag., 25, 191-200, doi: 10.1007/s11269-010-9694-9. [Link]

Cheng, K. S., I. Hueter, E. C. Hsu, and H. C. Yeh, 2001: A scale-invariant Gauss-Markov model for design storm hyetographs. J. Am. Water Resour. Assoc., 37, 723735, doi: 10.1111/j.1752-1688.2001 .tb05506.x. [Link]

Dubrovsky, M., I. Nemesova, and J. Kalvova, 2005: Uncertainties in climate change scenarios for the Czech Republic. Clim. Res., 29, 139-156, doi: 10.3354/Cr0291 39. [Link]

Eagleson, P. S., 1970: Dynamic Hydrology, McGraw-Hill, New York, 462 pp.

Eum, H.-I. and S. P. Simonovic, 2010: Integrated reservoir management system for adaptation to climate change: The Nakdong River basin in Korea. Water Resour. Manag., 24, 3397-3417, doi: 10.1007/s11269-010-96 12-1. [Link]

Fowler, H. J., S. Blenkinsop, and C. Tebaldi, 2007: Linking climate change modelling to impacts studies: Recent advances in downscaling techniques for hydrological modelling. Int. J. Climatol., 27, 1547-1578, doi: 10. 1002/Joc.1556. [Link]

Furrer, E. M. and R. W. Katz, 2008: Improving the simulation of extreme precipitation events by stochastic weather generators. Water Resour. Res., 44, W12439, doi: 10.1029/2008wr007316. [Link]

Hamlet, A. F. and D. P. Lettenmaier, 1999: Effects of climate change on hydrology and water resources in the Columbia River basin. J. Am. Water Resour. Assoc., 35, 1597-1623, doi: 10.1111/j.1752-1688.1999.tb042 40.x. [Link]

Hansen, J. W., 2002: Realizing the potential benefits of climate prediction to agriculture: Issues, approaches, challenges. Agric. Syst., 74, 309-330, doi: 10.1016/S03 08-521 x(02)00043-4. [Link] 
Huff, F. A., 1967: Time distribution of rainfall in heavy storms. Water Resour. Res., 3, 1007-1019, doi: 10.10 29/Wr003i004p01007. [Link]

IPCC, 2007: Summary for policymakers. In: Solomon, S., D. Qin, M. Manning, Z. Chen, M. Marquis, K. B. Averyt, M. Tignor, and H. L. Miller (Eds.), Climate Change 2007: The Physical Science Basis, Contribution of Working Group I to the Fourth Assessment Report of the Intergovernmental Panel on Climate Change, Cambridge University Press, Cambridge, 996 pp.

Kilsby, C. G., P. D. Jones, A. Burton, A. C. Ford, H. J. Fowler, C. Harpham, P. James, A. Smith, and R. L. Wilby, 2007: A daily weather generator for use in climate change studies. Environ. Modell. Softw.,22, 17051719, doi: 10.1016/j.envsoft.2007.02.005. [Link]

Koutsoyiannis, D. and E. Foufoula-Georgiou, 1993: A scaling model of a storm hyetograph. Water Resour. Res., 29, 2345-2361, doi: 10.1029/93wr00395. [Link]

Kyselý, J. and M. Dubrovský, 2005: Simulation of extreme temperature events by a stochastic weather generator: Effects of interdiurnal and interannual variability reproduction. Int.J.Climatol., 25, 251-269, doi: 10.1002/ Joc.1120. [Link]

Lee, S., S. Abdul-Talib, and H. Park, 2012: Lessons from water scarcity of the 2008-2009 Gwangdong reservoir: Needs to address drought management with the adaptiveness concept. Aquat. Sci., 74, 213-227, doi: 10.10 07/s00027-011-0213-8. [Link]

Li, F., C. A. Shoemaker, J. Wei, and X. Fu, 2012: A new reservoir operation policy generation method (SOSM) using scenarios optimization (SO) and Surrogate Model (SM). In: Tan, H. (Ed.), Technology for Education and Learning, Advances in Intelligent Systems and Computing Volume 136, 679-688, Springer Berlin Heidelberg, doi: 10.1007/978-3-642-27711-5_90. [Link]

Li, X., S. Guo, P. Liu, and G. Chen, 2010: Dynamic control of flood limited water level for reservoir operation by considering inflow uncertainty. J. Hydrol., 391, 124132, doi: 10.1016/j.jhydrol.2010.07.011. [Link]

Mehrotra, R. and A. Sharma, 2007: Preserving low-frequency variability in generated daily rainfall sequences. J. Hydrol., 345, 102-120, doi: 10.1016/j.jhydrol.2007.08.003. [Link]

Nagesh Kumar, D., F. Baliarsingh, and K. Srinivasa Raju, 2010: Optimal reservoir operation for flood control using folded dynamic programming. Water Resour. Manag., 24, 1045-1064, doi: 10.1007/s11269-009-94 85-3. [Link]

Parlange, M. B. and R. W. Katz, 2000: An extended version of the Richardson model for simulating daily weather variables. J. Appl. Meteorol., 39, 610-622, doi: 10.1175/1520-0450-39.5.610. [Link]

Payne, J. T., A. W. Wood, A. F. Hamlet, R. N. Palmer, and D. P. Lettenmaier, 2004: Mitigating the effects of climate change on the water resources of the Columbia River basin. Clim. Change, 62, 233-256, doi: 10. 1023/B:Clim.0000013694.18154.D6. [Link]

Payne, R. W., S. A. Harding, D. A. Murray, D. M. Soutar, D. B. Baird, S. J. Welham, A. F. Kane, A. R. Gilmour, R. Thompson, R. Webster, R., and G. Tunnicliffe Wilson, 2007: The Guide to GenStat Release 10, Part 2: Statistics. VSN International, Hemel Hempstead.

Pickering, N. B., J. R. Stedinger, and D. A. Haith, 1988: Weather input for nonpoint-source pollution models. J. Irrig. Drain. Eng., 114, 674-690, doi: 10.1061/(AS CE)0733-9437(1988)114:4(674). [Link]

Pickering, N. B., J. W. Hansen, J. W. Jones, C. M. Wells, V. K. Chan, and D. C. Godwin, 1994: WeatherMan: A utility for managing and generating daily weather data. Agron.J., 86, 332-337.

Pilgrim, D. H. and I. Cordery, 1975: Rainfall temporal patterns for design floods. J. Hydraul. Div., 101, 81-95.

Racsko, P., L. Szeidl, and M. Semenov, 1991: A serial approach to local stochastic weather models. Ecol. Model., 57, 27-41, doi: 10.1016/0304-3800(91)90053-4. [Link]

Richardson, C. W., 1981: Stochastic simulation of daily precipitation, temperature, and solar radiation. Water Resour. Res., 17, 182-190, doi: 10.1029/Wr017i001p0 0182. [Link]

Richardson, C. W. and D. A. Wright, 1984: WGEN: A Model for Generating Daily Weather Variables. US Department of Agriculture, Agricultural Research Service, ARS- 8,83 pp.

Selker, J. S. and D. A. Haith, 1990: Development and testing of single-parameter precipitation distributions. $\mathrm{Wa}$ ter Resour. Res., 26, 2733-2740, doi: 10.1029/WR02 6i011p02733. [Link]

Semenov, M. A., 2008: Simulation of extreme weather events by a stochastic weather generator. Clim. Res., 35, 203-212, doi: 10.3354/cr00731. [Link]

Semenov, M. A. and R. J. Brooks, 1999: Spatial interpolation of the LARS-WG stochastic weather generator in Great Britain. Clim. Res., 11, 137-148, doi: 10.3354/ Cr011137. [Link]

Semenov, M. A., R. J. Brooks, E. M. Barrow, and C. W. Richardson, 1998: Comparison of the WGEN and LARS-WG stochastic weather generators for diverse climates. Clim. Res., 10, 95-107, doi: 10.3354/Cr0100 95. [Link]

Sharma, A., D. G. Tarboton, and U. Lall, 1997: Streamflow simulation: A nonparametric approach. Water Resour. Res., 33, 291-308, doi: 10.1029/96wr02839. [Link]

Simonovic, S. P. and L. Li, 2004: Sensitivity of the Red River Basin flood protection system to climate variability and change. Water Resour. Manag., 18, 89-110, doi: 10.1023/B:Warm.0000024702.40031.B2. [Link]

Solomon, S., D. Qin, M. Manning, Z. Chen, M. Marquis, K. 
B. Averyt, M. Tignor, and H. L. Miller, 2007: Climate Change 2007: The Physical Science Basis, Contribution of Working Group I to the Fourth Assessment Report of the Intergovernmental Panel on Climate Change, Cambridge University Press, Cambridge, 996 pp.

VanRheenen, N. T., A. W. Wood, R. N. Palmer, and D. P. Lettenmaier, 2004: Potential implications of PCM climate change scenarios for Sacramento - San Joaquin River Basin hydrology and water resources. Clim. Change, 62, 257-281, doi: 10.1023/B:Clim.00000136 86.97342.55. [Link]

Wilks, D. S. and R. L. Wilby, 1999: The weather generation game: A review of stochastic weather models.
Prog. Phys. Geogr., 23, 329-357, doi: 10.1177/03091 3339902300302. [Link]

Wood, A. W., D. P. Lettenmaier, and R. N. Palmer, 1997: Assessing climate change implications for water resources planning. Clim. Change, 37, 203-228, doi: 10. 1023/A:1005380706253. [Link]

Yen, B. C. and V. T. Chow, 1980: Design hyetographs for small drainage structures. J. Hydraul. Div., 106, 1055 1076.

Zhang, H., G. H. Huang, D. Wang, and X.Zhang, 2011: Uncertainty assessment of climate change impacts on the hydrology of small prairie wetlands. J. Hydrol., 396, 94-103, doi: 10.1016/j.jhydrol.2010.10.037. [Link] 